\title{
Conflitos de proximidade na mineração no vale do Rio Tijucas/SC
}

\author{
Conflicts of proximity in mining in the valley of Rio Tijucas/SC \\ Conflictos de proximidad en minería en el valle de Rio Tijucas/ SC
}

Recebido: 10/01/2021 | Revisado: 12/01/2021 | Aceito: 15/01/2021 | Publicado: 18/01/2021

Cláudia Ravazzoli

ORCID: https://orcid.org/0000-0002-7618-3435 Universidade Federal de Santa Catarina, Brasil

E-mail: claudiaravazzoli@yahoo.com.br

Luiz Fernando Scheibe

ORCID: https://orcid.org/0000-0002-5275-9671

Universidade Federal de Santa Catarina, Brasil

E-mail: scheibe2@gmail.com

\begin{abstract}
Resumo
A extração de agregados para construção civil no Vale do Rio Tijucas/SC teve início por volta do ano de 1900, e causou, em tempos mais recentes, uma série de impactos sociais e ambientais fazendo emergir conflitos do tipo 'de proximidade'. Conflitos de Proximidade é uma teoria ou metodologia desenvolvida pelo geógrafo francês Patrice Melé que caracteriza um determinado tipo de conflito social onde se valoriza os aspectos dos seus efeitos, tendo sido elaboradas quatro hipóteses de produção desses conflitos quais sejam: processo de territorialização, processo de transações sociais, construção de um espaço público intermediário e processo de atualização local da lei. Neste artigo buscamos verificar se essas hipóteses podem ser aplicadas aos conflitos da região do Vale do Rio Tijucas. A metodologia contou com revisão bibliográfica, saídas de campo e entrevistas. Concluímos que a metodologia francesa se aplica no estudo de caso brasileiro apresentado, podendo eventualmente ser utilizada em outros casos em nosso País.
\end{abstract}

Palavras-chave: Conflito; Geografia; Conflito de proximidade; Rio Tijucas.

\begin{abstract}
The extraction of aggregates for civil construction in the Vale do Rio Tijucas / SC began around 1900, and has, in more recent times, caused a series of social and environmental impacts, causing conflicts of the type 'proximity' to emerge. Conflicts of Proximity is a theory or methodology developed by the French geographer Patrice Melé that characterizes a certain type of social conflict where aspects of its effects are valued, having been elaborated four hypotheses of production of these conflicts, namely: process of territorialization, process of transactions social, construction of an intermediate public space and process of local updating of the law. In this article we seek to verify whether these hypotheses can be applied to conflicts in the Vale do Rio Tijucas region. The methodology included bibliographic review, field trips and interviews. We conclude that the French methodology is applied in the Brazilian case study presented, and may eventually be used in other cases in our country.
\end{abstract}

Keywords: Conflict; Geography; Proximity conflict; Rio Tijucas.

\section{Resumen}

La extracción de áridos para la construcción civil en el Vale do Rio Tijucas / SC se inició alrededor de 1900, y ha provocado, en tiempos más recientes, una serie de impactos sociales y ambientales, provocando el surgimiento de conflictos del tipo 'proximidad'. Conflictos de Proximidad es una teoría o metodología desarrollada por el geógrafo francés Patrice Melé que caracteriza un determinado tipo de conflicto social donde se valoran aspectos de sus efectos, habiéndose elaborado cuatro hipótesis de producción de estos conflictos, a saber: proceso de territorialización, proceso de transacciones social, construcción de un espacio público intermedio y proceso de actualización local de la ley. En este artículo buscamos verificar si estas hipótesis se pueden aplicar a los conflictos en la región de Vale do Rio Tijucas. La metodología incluyó revisión bibliográfica, viajes de campo y entrevistas. Concluimos que la metodología francesa se aplica en el caso de estudio brasileño presentado, pudiendo eventualmente ser utilizada en otros casos en nuestro país.

Palabras clave: Conflicto; Geografía; Conflicto de proximidad; Río Tijucas.

\section{Introdução}

Há registros de atividade de mineração no Vale do Rio Tijucas/SC desde a década de 1900, tendo a região se tornado um importante polo de produção cerâmica na década de 1970, quando produzia telhas, tijolos e lajotas com a exploração de 
jazidas de argila (Rouver, 1988). A partir dos anos de 1980, o rápido crescimento urbano de toda a região metropolitana de Florianópolis diversificou o setor de insumos para construção civil e estimulou, também, a extração de areia no Vale.

Desenvolvidas por empresas de micro ou pequeno porte, as atividades de mineração eram executadas em lavras pontuais, mais ou menos restritas aos limites de pequenas propriedades, caracterizando-se pela ausência de projetos ou estudo prévio que indicassem a qualidade ou a quantidade do minério a ser lavrado, e que demonstrassem a viabilidade econômica da lavra, assim como não havia acompanhamento por técnicos durante a execução da atividade. A estrutura organizacional era simplificada, do tipo familiar, marcada por relações de parentesco, onde o proprietário da terra era geralmente o diretor administrativo, encarregando-se das mais diversas funções, e a mão-de-obra não apresentava formação técnica específica (EIA, 2003).

O vale do Rio Tijucas concentra a maioria das áreas de extração de agregados para construção civil da Região da Grande Florianópolis, e contém os mais importantes depósitos, "tanto no leito de rios quanto em cavas abertas na sua planície de inundação, sendo que nessas cavas muitas vezes intercala-se extração de argila e de areia". (Zwirtes, 2016, p. 33). Ao somarmos os valores de produção dos municípios que fazem parte do Vale do Rio Tijucas, ou seja, Tijucas, Canelinha, São João Batista e Nova Trento, encontramos o total de 51,4\% da produção de areia e 79,3\% da produção de argila da região metropolitana (RAL DNPM 2013 como citado em Zwirtes, 2016). O consumo das matérias-primas da Grande Florianópolis coincide com o próprio quantitativo produzido: "no momento inexiste comércio extra-regional destas substâncias" (Zwirtes, 2016, p. 92).

O grande volume de produção ocorreu, entretanto, de forma desordenada, o que trouxe consequências para a região, já relatadas por Efigênia Almeida, em 1992:

A expansão do parque industrial cerâmico e a necessidade de quantidades cada vez maiores de matéria prima exigiram a mecanização da lavra, objetivando maior produção. Os pontos de extração de argila se multiplicaram rápida e aleatoriamente por todo vale, alcançando dimensões e profundidades cada vez maiores, devido à mecanização. A falta de pesquisas e, consequentemente, de conhecimento do posicionamento, continuidade e principais características do corpo mineral, dificultam o desenvolvimento da lavra. O resultado é a lavra predatória: cavas abertas em vários pontos do mesmo terreno, partes menos interessantes da camada de argila abandonadas no meio da cava, acúmulo de água proveniente de infiltrações e desperdício de matéria prima. A utilização de equipamentos modernos na lavra vem provocando profundas alterações na topografia do vale, agravadas pela falta de acompanhamento técnico adequado (Almeida, 1992, p. 41).

Somava - se já, às degradações descritas acima, o problema das extrações desordenadas de areia em leito de rio, com impacto nas propriedades ribeirinhas, como a perda de terreno pelas erosões das margens. Almeida (1992) estimou em sua pesquisa de campo que o total da área degradada seria de $3.334 .050 \mathrm{~m}^{2}$. O município de Canelinha era o mais atingido pelos impactos causados pela mineração, totalizando $1.749 .325 \mathrm{~m}^{2}$, seguido por São João Batista com $934.500 \mathrm{~m}^{2}$ e Tijucas com 650.225 m² (Almeida, 1992, p.90).

Além disso, ainda devemos incluir o problema da ilegalidade de grande parte das jazidas, cujas empresas extraiam matéria prima sem a devida autorização dos órgãos públicos licenciadores, seja outorga mineral, seja licença ambiental. Isso significa que eram pouco submetidas à fiscalização pública, indicando um distanciamento entre o exercício da atividade minerária e o Estado, e evidenciando a pouca importância histórica dada pelo governo federal às atividades de produção de agregados. Esses problemas provocaram a emergência de conflitos sociais que, em algum momento, induziram a comunidade a se organizar e buscar apoio institucional. Por volta do ano de 2001, algumas lideranças locais como agricultores e vereadores de São João Batista, começaram a reunir diversos documentos e dados relativos às atividades de mineração de areia e argila da região. 
Nesse mesmo ano de 2001 foi criado o Comitê de Gerenciamento da Bacia Hidrográfica do Rio Tijucas - Comitê Tijucas, através do Decreto Estadual № 2.918/2001, entidade essa vinculada ao Sistema Nacional de Gestão dos Recursos Hídricos (SINGREH) e que então passou a se constituir como o principal motor ou movimento contrário à mineração no Vale. Essa instituição propiciou a ampliação do debate, de uma escala que antes era local e pontual, para uma escala regional e mais unificada. O Comitê elaborou e apresentou um dossiê, junto ao Ministério Público Estadual de SC, que apontava a necessidade de que fossem revistos os parâmetros, até então adotados, no licenciamento e fiscalização da atividade.

O Ministério Público, na pessoa do Promotor de Justiça, o Sr. Dr. Luiz Eduardo Couto de Oliveira Souto, assumiu então a direção da mediação dos conflitos, e propôs a elaboração do Termo de Ajustamento Preliminar n ${ }^{\circ}$ 08/2001, envolvendo os Municípios de Tijucas, Canelinha, São João Batista, Nova Trento e Major Gercino. O termo preliminar apontava a necessidade da realização de um Estudo de Impacto Ambiental - EIA, e respectivo Relatório de Impacto Ambiental - RIMA, com objetivo de se realizar um diagnóstico da situação ambiental de todas as áreas e identificar as medidas técnicas a serem aplicadas (EIA, 2003).

Munido das informações técnicas levantadas pelo estudo, o Termo de Ajustamento de Conduta - TAC da mineração do Vale do Rio Tijucas foi firmado em 02/08/2005 no Município de Tijucas e teve como objetivo gerir os conflitos instaurados na região e disciplinar as atividades de extração, beneficiamento e transporte dos empreendimentos de mineração de areia em leito de rio ou cava, argila em cava e mineração de argila ou saibro de encosta.

O objetivo do presente artigo é, portanto, avaliar a aplicação das "quatro hipóteses de produção de conflito" delineadas pela teoria/metodologia do Conflito de Proximidade, desenvolvida pelo geógrafo francês Patrice Melé, nos conflitos observados no Vale do Rio Tijucas, desencadeados pela atividade de mineração de agregados para construção civil.

\section{Metodologia}

Para alcançarmos os objetivos propostos neste trabalho, foi necessário um conjunto de metodologias, todas de natureza qualitativa, pois buscamos analisar um estudo de caso nacional (atividade de mineração do vale do Rio Tijucas/SC) sob a perspectiva da teoria da 'Geografia dos Conflitos' francesa, com ênfase na metodologia dos Conflitos de Proximidade desenvolvida pelo geógrafo Patrice Melé, ao qual descreveremos mais adiante, pois aprofundá-la é a própria intenção deste artigo.

O "estudo de caso é uma descrição e análise, a mais detalhada possível, de algum caso que apresente alguma particularidade que o torna especial" (Pereira, p.54), e que pode contribuir para construção do conhecimento. Para tal estudo, utilizamos revisão bibliográfica relacionada aos aspectos históricos e geográficos da realidade local bem como observações de campo e entrevistas aplicadas na região.

\section{Resultados e Discussão}

Segundo os geógrafos franceses Subra (2008), Torre et al (2010), Gerardot e Lemarchand (2011) e Melé (2013) há, atualmente, uma crescente tendência de realização de pesquisas relacionadas a situações que envolvam conflitos, seja dentro ou fora da ciência geográfica, não se limitando a um tipo, mas abarcando uma ampla variação de escalas de aproximação, de intensidades, de tipologias e denominações.

Essa tendência pode ser explicada pelo fato de que o estudo de conflitos se mostra como um importante analisador social na medida em que essas manifestações são reveladoras (Melé 2003, 2007, 2013; Cadoret 2006; Charlier, 1999): reveladoras das relações de forças presentes, da origem profunda das oposições (Cadoret, 2006) e da situação política em questão. Enfim, revela as falhas, as tensões e as contradições de um sistema social e/ou político-administrativo e mesmo a 
resistência a mudanças de certos grupos, porque o conflito possui a capacidade de tornar públicas as rivalidades latentes.

Sendo reveladores, os conflitos são para as partes envolvidas "um meio de criar um equilíbrio de poder" (...) e "podem, portanto, ser analisados como formas de produção negociada do ambiente urbano vivo" (Melé, 2003, p. 15), e por isso o conflito seria uma estratégia de conquista do espaço político público. Essa visão permite analisar os conflitos sob uma dimensão de ação coletiva e de regulação social, sendo um importante vetor de transformação.

Nessa perspectiva Melé (2013) propõe considerar as situações de conflitos como sistemas de ação, e não como movimento ou uma identidade marcada por uma essência. Esses sistemas de ação são marcados pelas relações entres os atores envolvidos bem como com atores externos, como atores não mobilizados. Essa noção também estabelece uma relação entre conflito e tomada de consciência, quando Melé (2012) afirma que o conflito é que constitui e organiza o ator, ou seja, o conflito forma um ator coletivo consciente das questões da mobilização.

\subsection{Definição de Conflito}

O conflito é definido por Melé (2003) como "uma situação, "um momento" de manifestação de protesto ou oposição, manifestação essa que "pode tomar a forma de uma estratégia de mídia, denúncia pública, atos de desobediência civil, distúrbios da ordem pública e ou recursos legais, constituição ou modificação de um equilíbrio de poder" (Melé, 2003, p. 4). Após uma ampla pesquisa bibliográfica sobre as variadas definições de conflito durante a elaboração de sua tese, Charlier (1999) concluiu por uma definição mínima, que perpassa todas as definições por ele identificadas e que pode ser expressa como sendo uma situação de oposição entre duas categorias de atores com interesses momentaneamente diferentes.

Os conflitos são gerados então pela rivalidade, competição, confrontação entre duas entidades dominantes concorrentes (grupos sociais, indivíduos, instâncias políticas), ou resistência de grupos ou indivíduos oprimidos em luta contra seu opressor, luta por justiça - e podem ser latentes ou manifestados.

Mas Charlier (1999) também acrescenta que todas as sociedades aceitam alguma intensidade da desordem social e que há crise(s) e conflito(s) quando as tensões ultrapassam o limiar de aceitação definido por cada sociedade. No desenvolvimento do estudo de geografia do conflito, Melé se ocupa fundamentalmente em questionar a produção e os efeitos sociais e territoriais dos conflitos. "Pode-se supor que o momento do conflito modifica a percepção/representação de um projeto, das autoridades públicas em questão e de um espaço apresentado a ser preservado". Mais adiante complementa dizendo que "nesse sentido o momento do conflito não é apenas um momento de enunciação que revela elementos do contexto social e político (...), mas um momento de sua produção" (Melé, 2003, p.6).

Para o autor, o conflito produz atos, discursos, territorialidades, espaços públicos de negociação, atualizações legais, além de conscientização social do funcionamento do aparato político administrativo, e tem também um papel de estruturação social, na medida em que "produz associações, alianças e coalizões, multiplicando interações entre os participantes" (Melé, 2003, p.6), podendo ser ao mesmo tempo includente e excludente.

Sendo produtores de novas possibilidades e materialidades, o autor afirma que "muitas pesquisas mostram que conflitos e controvérsias não são disfunções da ação pública, mas uma modalidade generalizada de sua implementação. Eles representam uma das modalidades de relacionamento entre os habitantes e a ação pública territorializada" (Melé, 2003, p.15). Nessa perspectiva, podemos compreender o conflito como uma forma positiva de socialização, "como um momento de aprendizado, da exposição dos moradores ao Estado de Direito e ao sistema político administrativo, como momento de socialização política e legal” (Melé, 2012).

O termo "conflito de proximidade" foi proposto por Melé de forma inaugural a partir do Projeto CONFURB intitulado “Conflits de proximité et dynamiques urbaines", desenvolvido no período de 2007 a 2010. Segundo o próprio autor, o conceito 
é utilizado para descrever situações que envolvam grupos mobilizados para controle de seu espaço de residência ou seu espaço próximo, ou seja, não é somente por competição pelo uso do espaço.

A noção de proximidade inerente ao termo não é suscetível a uma delimitação territorial ou uma medida objetiva, a definição de proximidade que retemos é a dada pelos residentes ou usuários quando estes afirmam que um projeto, uma atividade ou uma prática afeta seu ambiente. Isso implica que a distância entre os objetos, atividades ou práticas em causa pode ser maior ou menor, desde que estes conflitos se manifestem através de ações coletivas, durante as quais os grupos realizam um trabalho de (re)definição de sua inscrição espacial e territorial (Melé, 2012, p. 3).

$\mathrm{O}$ autor, ao elaborar a sua definição, desassocia a figura da proximidade à dimensão espacial de base material das perturbações ou dos impactos dos projetos, mas leva em consideração a importância das percepções e representações dos riscos e perturbações que proclamam uma capacidade de ver o que os outros não veem, ou ainda de reinterpretar os efeitos da proximidade. Assim, interagem os aspectos das distâncias físicas, as representações e as bases relacionais e por isso têm muito a contribuir para a geografia.

Como exemplo desse tipo de confronto, Melé (2012) cita situações de conflitos por vizinhança não desejada, mobilização pela preservação de uma paisagem, transtornos provocados por barulho de aviões e poluição atmosférica, sendo que a maior parte estão relacionados à mobilização contra projetos implementados pelos atores públicos , mas há também em razão de projetos privados ou mesmo entre diferentes grupos de população, não restringindo aqui se as mobilizações são realizadas por usuários ou produtores.

Enquanto metodologia, o estudo desse tipo de conflito está, portanto, centrado na produção e efeitos das situações estudadas, focando atenção sobre as produções territoriais, jurídicas e políticas (Melé 2012, 2013). Dentro dessa perspectiva o autor lança quatro hipóteses de interpretação sobre a produtividade dos conflitos, que envolvem processos e dinâmicas que se sucedem em seu interior, e os quais veremos mais adiante.

Segundo o sociólogo e urbanista mexicano Duhau (2013) e Melé (2013), os protagonistas dos conflitos de proximidade estão associados à noção de cidadãos (sociedade civil) e aparecem ao mesmo tempo em que surgem as instâncias de participação e consulta pública, por volta dos anos de 1990 (Melé, 2013). Esses protagonistas "começam [então] a se construir como um novo ator legítimo ao lado de outros movimentos sociais consolidados como a classe trabalhadora, os setores populares urbanos, a classe média e o campesinato" (Duhau, 2013, p. 75).

Esse novo regime político se processa na América Latina em geral no contexto da abertura democrática e traz mudanças de caráter institucional e legal, incluindo práticas de participação social e política que se refletem na organização do território nacional, e que coincidem com a inauguração da proteção ambiental (Duhau, 2013, p. 72).

São novos protagonistas porque, segundo Duhau (2013), a abertura ao desenvolvimento da cidadania e de práticas cidadãs participativas vão abrir espaço para a emergência de manifestações e exigências de direitos políticos sociais, transformando o cidadão comum em protagonista. Nesse contexto nascem os conflitos do tipo "de proximidade", que cumprem aqui um papel de criar um espaço público de debate. Assim as análises dos conflitos territoriais começam a ganhar nova roupagem com o exercício e a reivindicação de direitos e a construção de um espaço público no qual sejam resolvidos problemas de interesse geral. Além disso, "os conflitos territoriais começam a se referir à sociedade civil como uma entidade que reivindica autonomia perante o Estado e que possui capacidade legítima para intervir e assumir problemas de interesse público (Duhau, 2013, p. 75).

Para Melé (2013) as mobilizações de proximidade podem ser lidas como situações nas quais se misturam problemáticas de territorialidade e de cidadania, ou seja, quando há reivindicação dos residentes para fazer valer suas posições e para que ocorra a participação nas definições de interesse público, "uma vontade de intervenção política sobre uma base local" 
(Melé, 2013, p. 41) que, ainda segundo o autor, pode ser classificada como capacidade de agir ou de empoderamento.

No nosso estudo de caso, os conflitos deflagrados em um primeiro momento pelos ribeirinhos e/ou agricultores não ocorreram por estes serem contrários à atividade da extração em si, pois esses grupos sociais não defendiam um modelo de sociedade que não utilizasse mineração na construção de sua base material, nem tão pouco os embates ocorreram por concorrência pelo uso do espaço, mas sim em razão dos transtornos sofridos em seus territórios que foram atribuídos à proximidade da atividade.

A partir da perspectiva da teoria / metodologia apresentada aqui, iremos lançar uma análise dos conflitos observados na atividade de mineração no Vale do Rio Tijucas, e verificar se as hipóteses de produção dos conflitos propostos pelo geógrafo francês Melé se aplicam em um estudo de caso brasileiro.

\subsection{As quatro hipóteses de produção dos conflitos de proximidade da mineração no Vale do Rio Tijucas}

A primeira hipótese, chamada de Processo de Territorialização (1), afirma que conflitos de proximidade produzem processos de territorialização, considerando produção territorial de um conflito, conforme Melé (2013), como um processo de construção de um grupo social contestador, ou uma rede de apoio. Apreendemos esse processo então como resultado de um movimento social que, no Vale do Rio Tijucas, iniciou no período de articulação local de pessoas que se organizaram em torno de uma "solidariedade de destino" (Melé, 2013), e a partir desta, buscam a legitimação de suas demandas.

A solidariedade de destino nasce a partir de um sentimento comum de injustiça, de que a lei que deveria garantir seus patrimônios não estava sendo cumprida e por isso a mobilização utiliza como estratégia o respaldo jurídico de seus territórios. A legitimação jurídica dos territórios é aqui uma camada importante a se considerar e sustentou, muitas vezes, as justificativas dos conflitos instaurados, bem como definiu as escolhas das instâncias de protestos e contestações. Por outro lado, há também que se levar em conta outras camadas de significação que dela se depreendem, que incluem o simbólico ou a lógica de uso estabelecida pela população local.

Os principais deflagradores dos conflitos foram os moradores, agricultores e pecuaristas, ou seja, se constituíam como um grupo social que era ao mesmo tempo usuário e produtor e tinham a sua lógica de vida construída diretamente no local.

Essa situação fez com que se gerassem conflitos inicialmente interpessoais e com o tempo foram se constituindo redes de mobilização local de denúncias que tinham como objetivo questionar e demandar a atuação dos setores públicos, exigindo a aplicação das regras do direito. A relação entre os atingidos pela atividade e as empresas mineradoras era tensa, havendo mesmo relatos de situações que envolviam ameaças de morte.

Parte desses moradores/produtores tinham importante representação política nas Câmaras de Vereadores, o que fez com que essa instância pública fosse a primeira a ser acionada, trazendo o debate para a escala municipal. Também algumas denúncias foram feitas para os órgãos públicos responsáveis pelo licenciamento e fiscalização da mineração. As tentativas de solução, no entanto, foram infrutíferas, não se consolidaram, e se percebeu que era necessária a intervenção de uma instituição com maior força política.

Considerando o exposto até aqui, observamos que as reivindicações eram de fundo territorial, e o território em questão era a propriedade privada ameaçada pela proximidade com o território da mineração que subvertia as normas estabelecidas, gerando as incompatibilidades. A região possui historicamente uma relação com a mineração que antecede ao próprio Código Mineral Brasileiro (1967), tendo sido constituídos 'territórios de referência' ou uma lógica social baseados em uma cultura exploratória. E podemos acrescentar que por muito tempo essa lógica funcionou e inclusive deu ao local o status de polo cerâmico do Estado de Santa Catarina. Contudo, com as transformações sociais ocorridas na sociedade, começou a haver pressão para que algumas práticas fossem mudadas. 
Assim, outros elementos foram sendo agregados aos poucos à realidade social local; a atividade que era aceitável em um determinado período passa a se tornar um problema e crescem as tentativas para tentar excluí-la do Vale, situação à qual Charlier (1999) chama de surgimento da simultaneidade das incompatibilidades.

Em 2001, é criado o Comitê de Gerenciamento da Bacia do Rio Tijucas (Comitê Tijucas), que rapidamente assume o papel de representar o grupo contrário à mineração, vindo inclusive a se integrar no processo de construção coletiva do TAC proposto pelo Ministério Público em 2005 e dando mais força e legitimidade às reivindicações, ao contribuir para a incorporação do discurso ambiental no debate. O Comitê é revestido de um poder técnico, científico, e ao mesmo tempo de poder legítimo, pois é criado legalmente e tem poder gestor e deliberativo, e poder de referência, pois se constrói como uma dimensão carismática e de referência na região.

$\mathrm{Na}$ atuação do Comitê Tijucas podemos constatar explicitamente a sua postura voltada a combater a atividade de mineração. $\mathrm{O}$ formato dessa atuação constrói um ator social articulado em torno de dois campos territoriais: primeiro na defesa da propriedade privada dos atingidos, e o segundo na defesa do território ambiental, sendo que os primeiros não têm incorporado em sua prática o que vem defender o segundo, ou seja, os proprietários rurais não têm uma prática de preservação ambiental - aspecto que é pouco mencionado nos debates. Embora o Comitê fosse um fórum coletivo onde deveriam estar representados todos os usuários dos recursos hídricos na região, havia pouca ou nenhuma presença dos mineradores.

A entrada do Comitê e o consequente fortalecimento do discurso ambiental provoca o que Melé (2013) chama de 'ampliação da coletividade afetada' e contribui significativamente para a consolidação do conflito como um problema público ao ampliar a sua escala de atuação, da local para uma escala regional, alargando o processo de territorialização do debate para toda a Bacia Hidrográfica do Rio Tijucas.

Por outro lado, podemos observar também que, da mesma forma, o processo estimulou a territorialidade dos próprios mineradores, que ao se regularizar e se legalizar, trouxe como resultado um respaldo legal para sua atividade. Por ocasião da formulação do TAC, o grupo conseguiu se fazer mais coeso e unido, e a categoria se encontrou territorialmente mais fortalecida após o processo de transação porque o respaldo legal permitiu a continuidade de suas atividades. Nesse contexto se fortalece também o quadro técnico de apoio às empresas, que é representado por geólogos e engenheiros de minas que dão a elas o apoio profissional, exercendo uma força de legalização e regularização dentro das minas.

Outro ator social fundamental a ser considerado aqui são os órgãos públicos fiscalizadores que exercem principalmente o poder de polícia. Esses organismos juntamente com o MP representam o Estado. A presença e a atuação dessas entidades públicas no Vale cresceram significativamente, pois desse crescente exercício de fiscalização dependia o sucesso do TAC. Esses órgãos, poderíamos dizer, aumentaram a vigília na região cumprindo seu papel social de controle, seja do bem mineral, seja do bem ambiental, fortalecendo seu processo de territorialização no vale.

O esquema abaixo (Figura 1), elaborado pela autora baseado em Charlier (1999) e Lecourt (2003), organiza o processo de evolução espacial/territorial do fenômeno exposto até aqui em três momentos. O momento ' 1 ' expressa a etapa inicial em que as contestações sociais ocorriam em escala local (espaço da contestação). A Figura também demonstra que o espaço ocupado pela atividade de mineração não é todo ele objeto de contestação, mas apenas a área das minas que, pela proximidade, causam transtornos com a vizinhança. Ou seja, o 'espaço da atividade contestada' não coincide totalmente com o 'espaço do conflito'. O momento '2' representa a entrada do Comitê Tijucas, que passa a articular as contestações em escala regional, e por isso, há uma ampliação escalar do 'espaço da contestação'. No momento '3' ocorre a criação do espaço de mediação pelo MP e a entrada dos demais órgãos públicos no debate, o que amplia o alcance das discussões para as esferas institucionais estadual e federal. 
Research, Society and Development, v. 10, n. 1, e36810111848, 2021 (CC BY 4.0) | ISSN 2525-3409 | DOI: http://dx.doi.org/10.33448/rsd-v10i1.11848

Figura 1 - Processo de ampliação do conflito - organização espacial evolutiva.

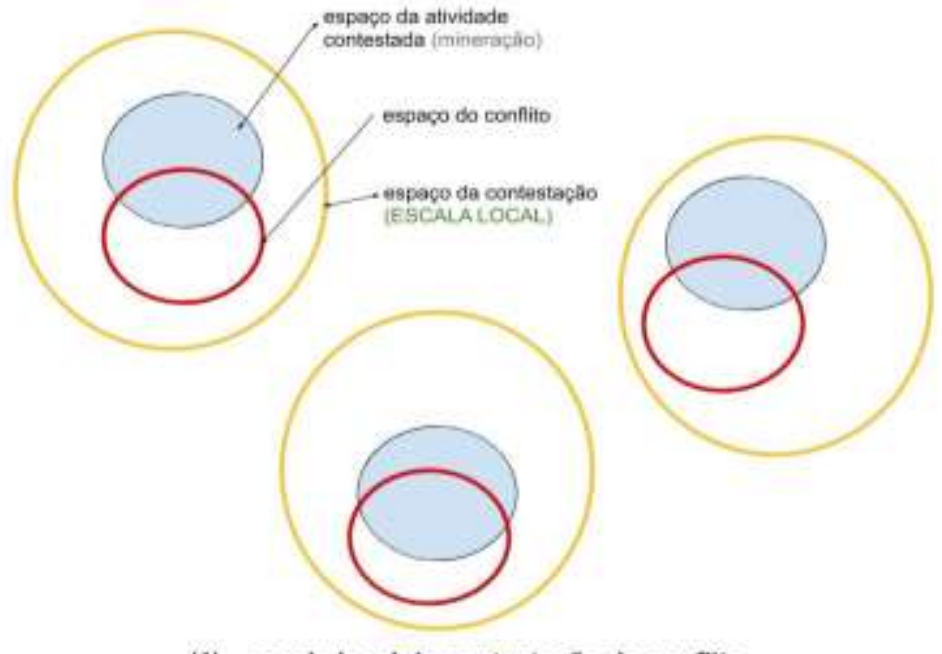

(1) escala local de contestaçāo do conflito

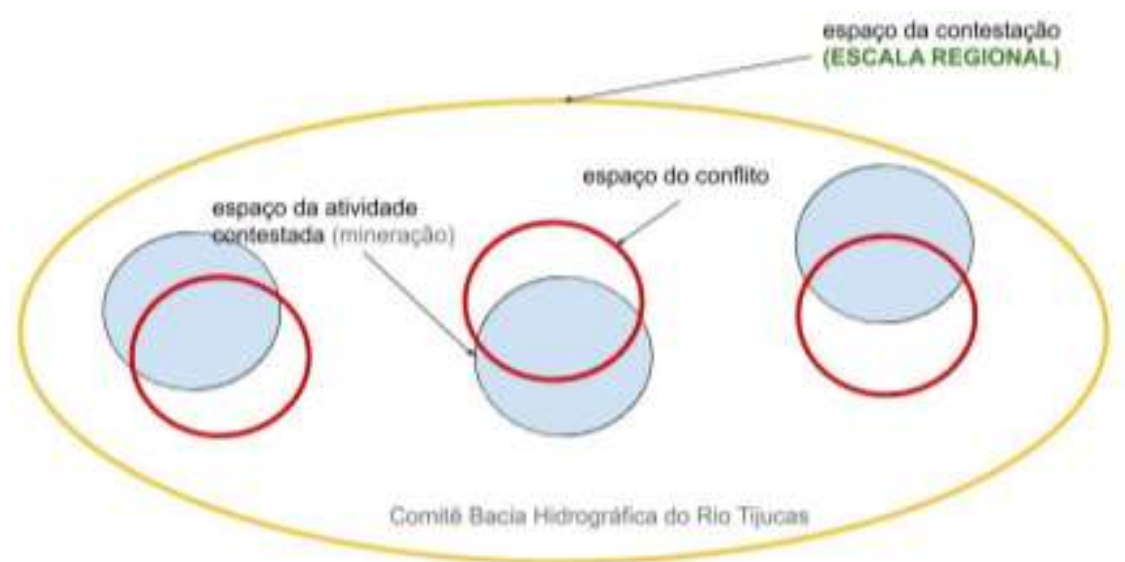

(2) Escala regional da contestação do conflito

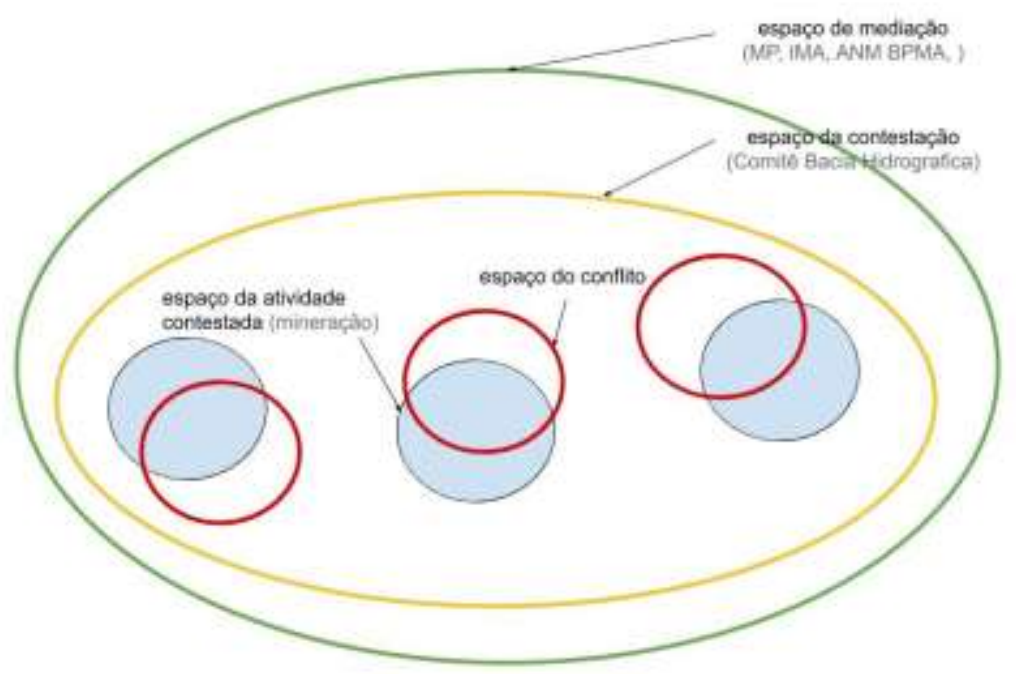

(3) escala regional de contestaçāo e espaço da mediaçăo incluindo órgăos públicos estaduais e federal

Fonte: Autores, com base em Charlier (1999) e Lecourt (2003). 
Podemos depreender como um todo que o resultado desse processo social provocou um 'territorialização reflexiva', qualificação essa denominada por Melé (2009) para coletivos que construíram uma cena na qual foram postas em debate informações sobre as qualidades, as evoluções e o futuro possível de um território, e desenvolveram mecanismos coletivos de procedimentos de vigilância.

A segunda hipótese de produção dos conflitos de proximidade que abordaremos é o chamado Processo de Transação Social (2) que, em nossa avaliação, surge como um 'coroamento' da legitimação do conflito e dos atores sociais envolvidos. O processo de transação social atua no sentido de provocar um rearranjo ou uma busca de um novo equilíbrio dos poderes locais.

No vale do Rio Tijucas, a transação social foi um processo complexo e longo que se deu em algumas etapas mediadas pelo Ministério Público Estadual, que utilizou como principal instrumento formal o Termo de Ajustamento de Conduta (TAC), mecanismo extrajudicial de busca de consenso que segundo De Mio (2005), Coelho (2013) e Viégas (2013), vem sendo utilizado de forma bem diversa e, por vezes, contraditória no Brasil.

O Ministério Público utilizou como estratégia reunir todas as partes envolvidas no conflito, incluindo os órgãos públicos estaduais e federal de gestão e fiscalização - IMA, Polícia Ambiental, ANM - e os representantes municipais, o que lhe possibilitou conduzir de forma mais integrada e articulada a situação, conforme exigia o caso. Além desses, foram chamados a participar profissionais de outros estados, especialistas na área, para contribuir na elaboração dos itens que compuseram o Termo, favorecendo uma construção coletiva mais isenta.

O processo de negociações iniciou em 2001 com o Termo de Ajustamento de Conduta Preliminar n ${ }^{\circ}$ 08/01. Na sequência foi elaborado o Estudo de Impacto Ambiental apresentado através de Audiência Pública e por fim culminou a formalização do TAC no ano de 2005, o que se deu em três reuniões chamadas na ocasião de workshops. Os momentos de definição de cada condicionante que integrou o TAC foram de intensa negociação, pois cada uma das partes buscou validar sua posição, tendo o Promotor de Justiça atuado de forma pacificadora, e as decisões foram sendo tomadas de forma consensual, sendo que a noção de consenso marcou esse processo. Ao que tudo indica, embora não tenham sido acatadas todas as posições, não ficou o sentimento, para nenhuma das partes, de que houve uma postura de favorecimento, e sim que restou um documento arduamente construído a partir de negociações.

Importante assinalar que o campo das forças sociais atuantes no fenômeno conflitual não possuía uma grande discrepância em seu interior, sendo um debate mais ou menos equilibrado, formado praticamente só por setores produtivos locais. O período que se sucedeu às transações foi fundamental para garantia da efetividade do termo, que se deu através de fiscalizações por vezes conjuntas e por vezes individuais, demandadas e supervisionadas pelo Promotor Público.

A falta de rito padronizado do Termo, denunciada por Viegas (2003) como uma porta de realização de interesses econômicos privados, atuou de forma positiva no Vale do Tijucas na medida em que essa flexibilização permitiu que o termo tivesse sido construído a partir da realidade e das necessidades locais, conforme defendido por De Mio (2005), o que pode ter contribuído para sua efetividade e amplo reconhecimento. A participação e a publicidade foram fundamentais como formas de controle dos processos de sua elaboração.

A reflexão sobre a Construção de um Espaço Público Intermediário (3), terceira hipótese, conforme proposto por Melé (2013), deve envolver todo o fenômeno conflitual desde o momento em que começa a se tornar um debate público. Em nossa compreensão, esse processo está diretamente relacionado ao processo de territorialização, talvez até mesmo constitua o próprio. A separação e ao mesmo tempo o necessário diálogo entre as dimensões geográficas 'espacial' e 'territorial' aparecem desde Charlier (1999) e Lecourt (2003), e assinalam a percepção de espaço como suporte físico, e o território como espaço político relacional. Embora constituam noções separadas, entendemos que a análise deve ser integrada, pois o processo territorial demanda necessariamente um suporte físico. 
Podemos considerar em nosso estudo de caso que os espaços públicos intermediários foram instaurados em dois momentos importantes. Em um primeiro momento ocorreu a etapa preparatória, quando os habitantes que se sentiam atingidos pela prática da mineração local recorreram aos seus pares na Câmara de Vereadores, onde se iniciou um debate preliminar, cuja estratégia adotada foi a busca pelo apoio do Comitê de Bacia Hidrográfica. O Comitê Tijucas passa a se tornar o principal espaço de debate e de fortalecimento e afirmação das territorialidades, que será o principal eixo de argumentação por ocasião da mediação do conflito. Os debates do Comitê se dão, principalmente, através de reuniões, Assembleias, Seminários abertos ao público, projetos junto às escolas entre outros, e como meio de divulgação de suas práticas e demandas utilizam a internet.

Essa primeira etapa de articulação já se constituiu como um momento onde um debate público é instaurado e preparado para o segundo momento, quando chega ao MP. No MP o processo foi ampliado com a inclusão de novos atores institucionais para elaboração do TAC.

Esse segundo momento se constitui então como um amplo espaço de debate democrático onde todos foram ouvidos e puderam exercer sua cidadania, onde as negociações resultaram no fortalecimento das territorialidades locais na medida em que se adequaram às normas e passaram assim a serem reconhecidas as suas legitimidades. $\mathrm{O}$ local utilizado para intermediar $\mathrm{o}$ debate foi principalmente a Universidade do Vale do Itajaí - UNIVALE, uma instituição comunitária de ensino superior. Assim, podemos afirmar que o conflito provocou um processo de construção de um espaço público intermediário de debate de fato.

Os conflitos observados no Vale do Rio Tijucas desencadearam dois fenômenos relacionados à quarta hipótese chamada de Processo de Atualização Local da Lei (4): demanda pelo cumprimento da lei já existente e a criação de uma nova norma. Em um primeiro momento a reivindicação dos opositores foi pela materialização da lei em nível local, a começar pela demanda pela legalização das minas que estavam operando em sua maioria fora da legalidade ambiental e/ou mineral, pois algumas empresas não possuíam título autorizativo e outras realizavam extração em áreas pertencentes a terceiros. Ou seja, a comunidade percebeu que o direito não se aplicaria sozinho e, portanto, tiveram que "agir" para tornar efetivas as regras no contexto local.

Nesse período também se constatou que não havia uma norma que regulamentasse e padronizasse a prática da atividade, dificultando inclusive uma uniformização nas vistorias fiscalizatórias, o que frustrava as atuações ou gerava exigências contraditórias. Esse fato foi um motivador para que o Ministério Público criasse um TAC do qual constasse uma série de normas técnicas. Além disso, as empresas mineradoras tiveram prazos para reunirem a documentação exigida, protocolarem junto ao Instituto de Meio Ambiente - IMA/SC e à Agência Nacional de Mineração - ANM, e solicitarem licença ambiental, iniciando assim o processo de legalização.

O TAC como uma forma de solução extrajudicial de conflitos tem como objetivo permitir um período de adequação do agir às exigências legais, no entanto, além disso, o termo assinado no Vale do Tijucas também veio suprir a falta de uma normatização estadual ambiental e foi tão bem sucedido que serviu de referência para a elaboração das diretrizes da Instrução Normativa - IN 07 - mineração/ IMA publicada em 03/07/2013, que tem, hoje, validade em todo o estado. Essa IN 07/2013 define a documentação necessária ao licenciamento e estabelece os critérios para apresentação dos planos e projetos ambientais para implantação de atividades de mineração. Interessante observar que mesmo após ter sido criada a norma espelhada nas condicionantes do TAC, o termo continua sendo considerado vigente, principalmente pelos órgãos que atuam em outras esferas, como as secretarias de meio ambiente municipais e a Agência Nacional da Mineração.

Com a transposição do conteúdo do TAC para uma norma estadual, os efeitos do conflito alcançam uma nova escala: escala estadual, conforme podemos observar na Figura 2, que adiciona uma nova camada à Figura 1. A criação da IN 07/2013, que atua em nível estadual, parece ser a produção mais expressiva do fenômeno social aqui pesquisado, trazendo modificações significativas na regularização da atividade minerária do Vale do Rio Tijucas, limitando sua prática ao mesmo tempo em que a 
legitima.

Figura 2 - A nova esfera ou escala de influência do processo do conflito.

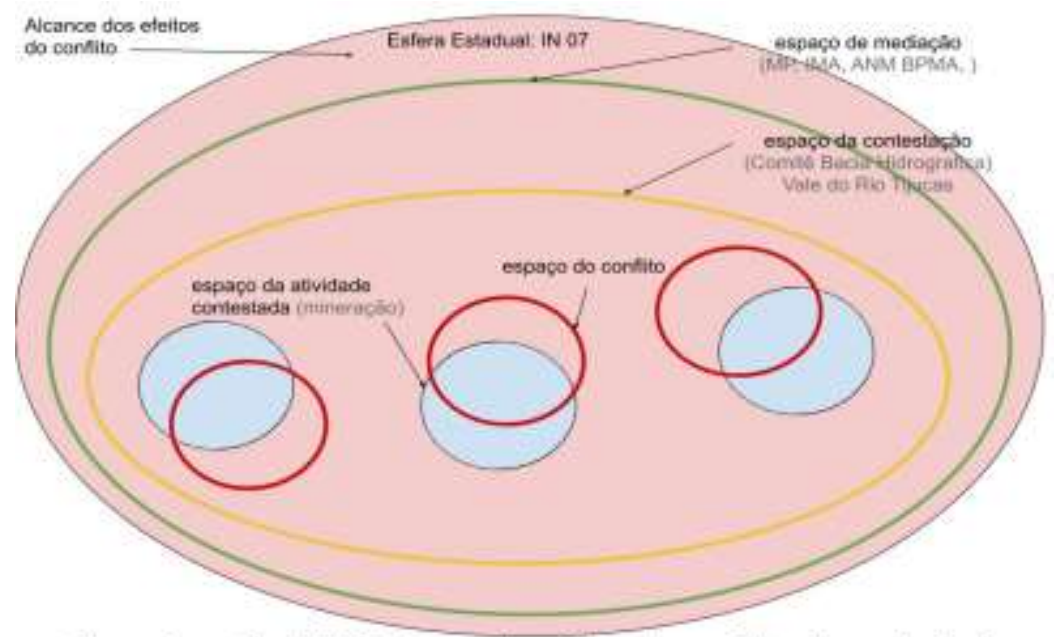

(4) escala estadual: IN 07 , alcance dos efeitos dos conflitos de proximidade

Fonte: Autores.

Essa ampliação da escala de influência do conflito para o nível estadual não foi uma estratégia utilizada por alguma das partes, mas foi resultado de uma construção social bem elaborada, que serviu para preencher uma lacuna normativa. Ao mesmo tempo em que os grupos locais tiveram capacidade de organização e de mobilização para reivindicar suas demandas, encontraram uma facilidade de acesso institucional ao Ministério Público e um ambiente político democrático e horizontal que conduziu o processo. Assim, a sociedade foi chamada a pensar e construir sua regulamentação e após a implantação deste acordo coletivo, embora ainda tenham persistido conflitos, observamos que os que se sucederam, se deram de maneira diferente, em outro nível de controvérsia, mudando inclusive o foco da problemática.

Ou seja, a IN07/2013, norma estadual, foi gestada durante o mecanismo de mediação do conflito, e por isso podemos afirmar que ela é consequência ou efeito desse conflito. Contudo, imediatamente após o momento da sua validação, ela passa a atuar, direcionar e gestar os rumos da prática espacial da mineração, se transformando em causa, perfazendo um movimento dialético de base material. A norma elaborada de forma conjunta traz elementos da prática local, bem como elementos da oposição e dos órgãos técnicos, não havendo uma supressão completa do que existia até então, mas um aprimoramento, e talvez aí resida a razão do seu sucesso.

\section{Conclusão}

Concluímos que a teoria/metodologia dos Conflitos de Proximidades do geógrafo francês Melé se adequou ao nosso estudo de caso e auxiliou a problematizar de forma mais complexa os conflitos identificados na região do Vale do Rio Tijucas, mostrando-se como uma boa ferramenta analítica. Observamos que os conflitos por nós estudados produziram os mesmos processos observados nas pesquisas elaboradas pela equipe de estudos coordenada por Melé (2003, 2011).

O processo de territorialização se deu em diferentes momentos nos grupos sociais envolvidos, e foi necessário e decisivo para impulsionar a eclosão do conflito local e desencadear todo o fenômeno estudado. O conflito também produziu processos de transação social importantes, cujo sucesso esteve ligado ao contexto político democrático, bem como às bases 
institucionais estabelecidas até aquele momento, e à postura e atuação do Ministério Público Estadual.

Não foi um acontecimento pontual, mas de fato um longo processo que envolveu alguns instrumentos de transação, tendo como ponto alto o TAC, mesmo que tenhamos constatado que os TACs que vêm sendo elaborados ao longo do território nacional possuem realidades bem distintas dessa, onde esse mesmo instrumento se torna refém de interesses econômicos e políticos.

Também foram produzidos espaços de gestão dos conflitos, onde o debate foi possível, e estabelecida a legitimação dos agentes envolvidos. A produção de atualização local da lei foi, para nós, o destaque da produção social gerada pelo conflito estudado. O Termo foi elaborado de forma coletiva ouvindo a realidade dos mineradores locais, e as suas cláusulas de ordem técnica foram tão bem estruturadas que estas foram utilizadas para elaboração de uma norma estadual IN 07/2013 do IMA. Ou seja, seus efeitos transitaram da escala local chegando à escala estadual de atuação.

Como sugestões de trabalhos futuros, sugerimos que novos conflitos sociais de natureza semelhante ao pesquisado aqui sejam analisados sob a perspectiva da teoria/ metodologia dos Conflitos de Proximidade e averiguada a validação das quatro hipóteses de produção desses, bem como a possibilidade de construção de novas hipóteses.

\section{Referências}

Almeida, E. S. (1992) O Pólo Cerâmico no Vale do Rio Tijucas: análise da exploração mineral e da degradação ambiental [Dissertação de mestrado, Universidade Federal de Santa Catarina].

Cadoret, A. (2006). Les conflits d'usage liés à l'environnement sur le littoral du Languedoc Roussillon: Réseaux d'acteurs sociaux et médiation pour une gestion intégrée [Thèse de Doctorat, Université Paul Valéry].

Charlier, B. (1999). La défense de l'environnement : entre espace et territoire. Géographie des conflits environnementaux déclenchés en France depuis 1974. 1999 [Thèse de Doctorat, Université de Pau et des Pays de l'Adour].

Coelho, M. L. D. (2013). A (in)efetividade dos Termos de Ajustamento de Conduta no enfrentamento à degradação socioambiental provocada pelos lixões na Região Metropolitana de Belo Horizonte [Dissertação de mestrado, Escola Superior Dom Helder Câmara ESDHC].

De Mio, G. P. (2005). O inquérito civil e o termo de ajustamento de conduta como instrumentos efetivos para resolução de conflitos ambientais: a experiência da promotoria de justiça do meio ambiente da comarca de São Carlos-SP [Tese de doutorado, Universidade de São Paulo].

Duhau, E. (2013). Conflitos de Proximidade no México: entre a violência e a mobilização da lei. In Melé, P. (Org.), Conflitos de proximidade e dinâmica urbana (pp. 71 - 92) Rennes University Press.

Estudo de Impacto Ambiental. (2003). Mineração Rio Tijucas. Caruzo Jr.

Gerardot, M. \& Lemarchand, P. (Org.). (2011). Géographie des Conflits. Atlante.

Instrução Normativa $\mathrm{N}^{\circ} 07$, de 03 de julho de 2013. Define a documentação necessária ao licenciamento e estabelecer critérios para apresentação dos planos, programas e projetos ambientais para implantação de atividades de mineração. IMA, Santa Catarina. Recuperado de: https://www.ima.sc.gov.br/index.php/licenciamento/instrucoes-normativas.

Melé, P. (2013). Analyse des conflits et recherches françaises: le moment agonistique? In Melé, P. (org.) Conflits de Proximité et dynamiques urbaines. Presses universitaires de Rennes.

Melé, P. (2007). Conflits locaux: de nouvelles scènes de production territoriale? Territoires, 42-44.

Melé, P. (2003). Conflits, territoires et action publique. In P. Melé, C. Larrue, M. Rosemberg. Conflits et territoires (pp.13-32). Presses universitaires François Rabelais.

Melé, P. (2012). Pour une géographie des conflits urbains de proximité. In Géocarrefour. Amérique Latine, 87/1, 3-13.

Pereira, A. S. et al. (2018). Metodologia da pesquisa científica. UAB/NTE/UFSM.https://repositorio.ufsm.br/bitstream/handle/1/15824/Lic_Computacao_ Metodologia-Pesquisa-Cientifica.pdf?sequence $=1$

Rouver. V. (1988). Canelinha do Tijucas Grande. Canelinha: Editora da Prefeitura Municipal de Canelinha.

Subra, P. (2008). L'aménagement, une question géopolitique! La Découverte. Hérodote n 130, 222-250.

Torre, A.; Melot, R.; Bossuet L.; Cadoret A.; Caron, A., Darly, S.; Jeanneaux, P.; Kirat, T. e Haï Vu Pham. (2010). Comment évaluer et mesurer la conflictualité liée aux usages de l'espace? Eléments de méthode et de repérage. VertigO - la revue électronique en sciences de l'environnement Volume 10 Numéro 1. 
Research, Society and Development, v. 10, n. 1, e36810111848, 2021 (CC BY 4.0) | ISSN 2525-3409 | DOI: http://dx.doi.org/10.33448/rsd-v10i1.11848

Viégas, R. N. (2007). As resoluções de conflito ambiental na esfera pública brasileira: uma análise crítica. Confluências - Revista Interdisciplinar De Sociologia e Direito, 9(2), 23 - 49.

Zwirtes, S. (2016). Projeto materiais para construção civil da região da grande Florianópolis. Informe de Recursos Minerais. Série Rochas e Minerais Industriais, n. XIX, Programa Geologia do Brasil. Porto Alegre: CPRM. 